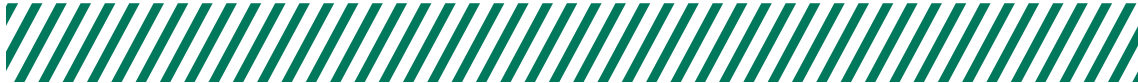

\section{Scrambling to Keep Up}

Dear Reader,

Many manufacturers see their future in electric vehicles, particularly in the passenger car sector, but not only there. As Egbert Fritzsche, CEO of the VDA Standards Committee for Automotive, states in a joint press release of VDA and VDE, "Heavy-duty vehicles will also be equipped with electric drives in the future to further reduce $\mathrm{CO}_{2}$ emissions in the mobility sector. The industry has such battery-electric vehicles in the development pipeline." I have my doubts that vehicle users, particularly in the heavyduty sector, will follow the wishes of politicians and manufacturers and also rely on these vehicles in the future. The reason for my doubts is that batteries are still the main problem, not to mention the situation regarding charging times and availability of charging stations.

"Larger traction batteries, for example, require higher charging power. The currently achievable charging power in the passenger car sector via the Combined Charging System (CCS) does not fulfill heavy duty vehicle requirements in all use-cases," says Dr. Ralf Petri, Head of Mobility and Logistics at VDE and Head of Department for Mobility at VDE/DKE. For this reason, experts have identified the requirements necessary to create appropriate standards in a kickoff workshop. However, those familiar with the work of standardization know just how long these processes can take. The tight timeline stipulate by politics regarding the reduction of $\mathrm{CO}_{2}$ emissions begs the question: Why has work on this only just begun?
Students in institutions of higher education are following the trend toward electromobility and alternative powertrains. Just a few years ago, lectures overflowed with topics relating to the combustion engine and today professors lament the lack of interest in this technology. The next problem is already on the horizon, since combustion engines, in whatever form, will be irreplaceable in the heavy duty sector for the next decades. If this development continues, we won't just be scrambling to keep up with the development of electric vehicles.
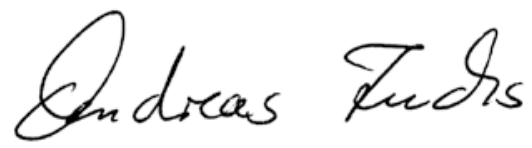

Andreas Fuchs

Responsible Editor

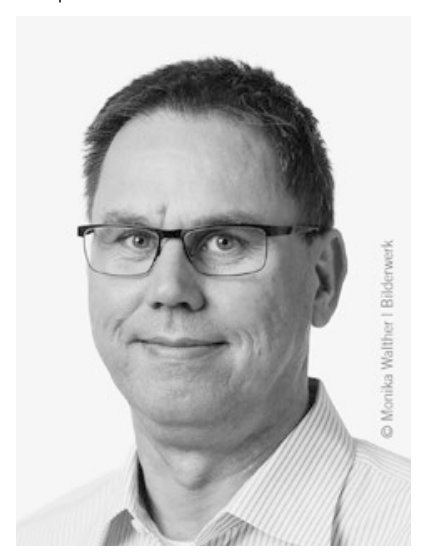

VISIONS. DEVELOPMENT. MOBILITY.

The world of mobility is changing. The challenge facing automotive developers is to acquire the knowledge they will need tomorrow without losing sight of future technologies. The complexity of the mobility transformation process calls for groundbreaking solutions. ATZelectronics provides the latest information from across the entire spectrum of automotive electronics. Take advantage of the interactive e-magazine and benefit from the extensive information in our unique online archive, which gives you the option of downloading PDF files.

\section{$A T Z$ electronics}

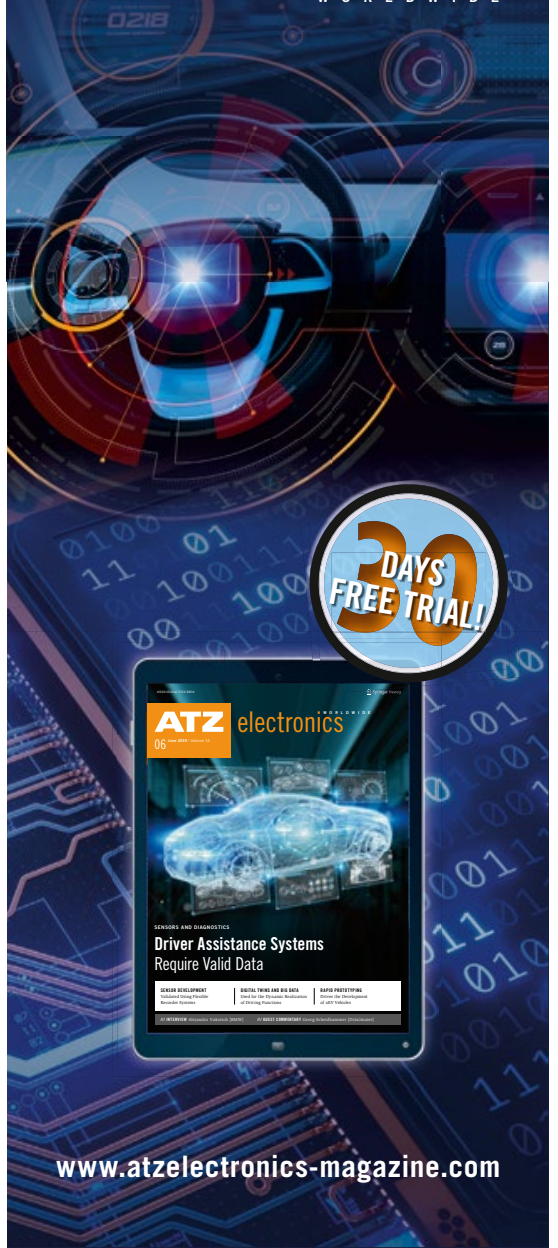

